\title{
Why Development of the Elderly Human Resources is Imperative
}

\author{
Mingjie Zhao* \\ School of Economics and Management \\ Beijing Jiaotong University \\ Beijing, China \\ 15120562@bjtu.edu.cn
}

Keywords-aging population; elderly human resource; demographic dividend; pension

\begin{abstract}
This paper focuses on how to develop the old human resources in the process of rapid population aging in our country, that is, how to avoid and weaken the number of the elderly population and the rapid growth of the total population in the population aging period to the economic and social negative Influence, play the positive effects of population aging. This paper focuses on the analysis of the development of human resources in the elderly from the following three perspectives: the demographic dividend and the aging of the population; the lack of pension ability; the change of the concept of old-age pension. The development of human resources for the elderly is of great significance to the success of China's response to the aging of the population and the maintenance of economic and social sustainable development. The government, enterprises and elderly individuals should work together to make the human resources of the elderly sustainable and develop in depth.
\end{abstract}

\section{Introduction}

Ageing population is the most prominent social phenomenon at the end of the 20th century, and it is also a major social problem that the world must face in the 21 st century. Internationally, the proportion of people over 60 years of age is $10 \%$ of the total population, or $7 \%$ of the total population is $65 \%$ of the total population as a country or region to enter the standard of aging society. By the middle of the twentieth century, most Western capitalist countries had entered the threshold of aging society. In 2000, China's population aged over 60 reached $10.46 \%$ of the total population. China officially entered the ranks of old-age countries. The problem of reducing the number of working-age population and the pension pressure brought by the aging of the population has brought profound influence to the economic society of our country. The development of the old human resources is an important measure to solve the negative impact of the process of population aging.

\section{Population dividend and population aging}

In general, the demographic dividend refers to the positive impact of population age structure advantage on economic growth in the process of population transition. With the development of the theory of population dividend, people understand their meaning more deeply, gradually derived from the "first population dividend" and "second population dividend" two-stage theory. "The first demographic dividend" is the traditional sense of the demographic dividend, mainly attributed to the supply of labor force; "second population dividend" mainly from the perspective of the quality of labor supply to explain the role of population for economic growth.

With the deepening of aging, the aging of the population brings to China's economic impact is mainly reflected in the following two aspects: one is caused by the fundamental transformation of China's labor force structure; the two is to gradually reduce the number of school-age workers. The source of the population dividend is the age structure advantage of the specific stage of the demographic transition. With the change of the population change stage, when the population age structure is aging, the "first demographic dividend" brought by the higher proportion of the working 
age Weaken or even disappear. In the long run, deepening the degree of aging will make the labor force growth rate decreased gradually and the proportion of the workforce declines, which led to the scale of labor supply decreases [1]. According to statistics released by the Bureau of statistics in January 2016: at the end of 2015, China's working age population aged 16 to 59, a net decrease of more than 2014 people by the end of 4 million 870 thousand. This is also the working age population for fourth consecutive years of decline. More and more severe aging of the population, making China's labor force from the "unlimited supply" to "Limited surplus", "demographic dividend" will gradually disappear, and the labor supply in 2030 to 2050 years into the most severe period, produced a great threat to the industrial structure and the competitive advantage of China [2].

"The first demographic dividend" for the disappearance of China's economic development is both an opportunity and a challenge, if we can take advantage of China from the "population" into "talent", China will be able to usher in the "second population dividend period." One of the main ways to excavate the "second demographic dividend" is to develop the existing labor force twice. The increasingly retired elderly group is the main object of the secondary development of human resources. The status quo of China's lack of high-tech talent provides the necessity for the development of elderly human resources, as well as the improvement of medical level and the upgrading of modern industrial structure provide the possibility for the development of elderly human resources.

\section{Pension sustainablity and aging population}

\section{A. Population Aging and Pension Sustainability}

At present, the lack of pension capacity in China can be considered from the following three aspects: lack of pension reserves; pension spending continued to increase; pension gap is widening. China's pension sustainability is insufficient due to a variety of reasons, but the aging of the population aggravated the lack of pension capacity. Specifically, the aging of the population is mainly due to the increase in the number of pensioners and the extension of the number of years to support the impact of pension sustainability.

According to the Ministry of human resources and social news, the trend of increasing population aging is irreversible. With the acceleration of aging, the number of retirees increased year by year, the burden of pension funds is growing. According to the 2016 released by the national office on aging "Chinese Population Aging Trend Prediction Research Report" predicts that by 2023, the number of the elderly population will increase to 270 million, and the population is equal to the number of children aged $0-14$, to 2050 , the total elderly population will exceed 400 million, aging level to more than $30 \%$, enter a severe aging society [3]. If the fertility rate has maintained a high level, the working population has always maintained a high proportion in the total population, the elderly population dependency is relatively low, so the following generation for the older generation who features the PAYG system as the basic support of the system, can ensure the effective operation of the first generation of the endowment insurance system. However, the aging of the population has broken the balance of the system, the relative contraction of the next generation has been unable to feed the older generation of the relative expansion of the previous generation.

At the same time, on October 25, 2016, the Central Committee of the Communist Party of China and the State Council issued the "Healthy China 2030" Plan, which stipulated that by 2030, China's major health indicators entered the ranks of high-income countries, with life expectancy increasing by 76.34 years, Will reach 79 years old [4]. The increase in the number of years of life makes China's pension spending more pressure.

\section{B. Development of the Elderly Human Resources to Ease the Pressure on Pensions}

The degree of aging is deepening, and the problem of the lack of pension sustainability is one of the measures to solve these problems. The implementation of a flexible retirement system, gradually extend the retirement age, on the one hand can increase the number of payment of pension, pension income scale expansion; on the other hand, can reduce the number of pensioners, reduce pension expenditure, thus greatly reduce the pension burden. 
One of the measures to solve these problems is the rational development of the elderly human resources. The implementation of flexible retirement system, and gradually extend the retirement age, on the one hand can increase the number of pension payments to expand the income scale of the pension; the other hand, reduce the number of pensioners in the current period, reduce the scale of pension expenses, thereby significantly reducing Pension burden.

China's current female workers retirement age is 50 years old, male workers retirement age is 60 years old, and developed countries generally more than 60 years of retirement age, such as the United States is 65 to 67 years old, Germany, Spain, Denmark, the Netherlands are 65 years old. Therefore, a progressive model can be adopted to implement a flexible retirement system and to gradually delay the retirement age. According to some researchers, director of the World Social Security Research Center of the Chinese Academy of Social Sciences, the retirement age of our employees is one year delayed. The pension fund can grow by RMB 4 billion and reduce the deficit by 16 billion yuan. The Decision of the Central Committee of the Communist Party of China (CPC) on the comprehensive deepening of reform of major issues passed by the Third Plenary Session of the Eighteenth Central Committee of the Communist Party of China (CPC) also made it clear that it was necessary to study the policy of establishing a progressive delayed retirement age. The Ministry of Human Resources and Social Security said that Delayed retirement program. The legalization of delayed retirement reform has a great effect on promoting the development of human resources in the elderly [5].

\section{The change of the concept of providing for the aged}

\section{A. From "Ageing of health" to "Healthy Ageing"}

The "Ageing of health" put forward in the 1980s was mainly based on the physical and mental needs of the elderly, rather than the social rights perspective of the elderly. In a certain sense, the theory of healthy aging has a positive social significance for maintaining the basic health of the elderly population and improving the quality of life. However, the theory implies two negative views: First, the elderly as a social burden Rather than the precious wealth of society; the second is from the perspective of the elderly needs, rather than the elderly population of social rights perspective, to look at the health of the elderly population.

In the late 1990s, the international community, based on the theory of social rights, put forward the concept and theory of a more comprehensive and more generalized aging than "healthy aging". First of all, "active aging" is no longer simply regarded as the burden of the elderly, but as an active creator of social wealth and social progress of the positive contributors; Secondly, from the constraints of the health of the elderly social factors To further explore the importance of income, participation and social protection for the health of the elderly; once again, given the state, government and society to ensure the health and development of the elderly responsibilities and obligations, so that the elderly get healthy, And the protection of the elderly as a social right.

After more than 10 years of exploration and development, countries have made remarkable achievements under the guidance of the active aging strategy, but because of the following two reasons, people have aroused the re-examination of the role of "health" in the process of population aging: Aging and population life expectancy extended, for the elderly medical expenses into a substantial increase; the other hand, the health equity issues highlighted [6]. Thus, on 1 October 2015, the United Nations International Day of Elderly Persons, the World Health Organization (WHO) issued the Global Report on Aging and Health, once again put the "healthy aging" on the agenda and with new ideas and Perspective of the interpretation of the healthy aging of the rich connotation and policy guidance. The new concept mainly includes the following aspects: the promotion of healthy aging is an investment; the impact of population aging on public health expenditure is lower than expected; "typical elderly" does not exist; "70 years old is not a new 60 years old " [7].

\section{B. Trajectories of Healthy Ageing}

In a new report, the World Health Organization defines Healthy Ageing as the process of developing and maintaining the functional ability that enables well-being in older age including 
intrinsic ability (Intrinsic capacity) and function play (functional ability) two aspects. The intrinsic ability refers to the integration of the physiological and psychological functions of the individual to the genetic basis of the individual characteristics, the influence function is interactive; elderly inherent ability and environment to realize the individual value, the environment here includes not only the family environment, living environment, interpersonal relationship and other micro environment, including the social the concept of public policy and other macro environment.

Healthy Ageing reflects the ongoing interaction between individuals and the environments they inhabit. This interaction results in trajectories of both intrinsic capacity and functional ability. To illustrate how these might be conceptualized and used, Fig. 1 shows three hypothetical trajectories of physical capacity for individuals beginning from the same starting point in midlife.

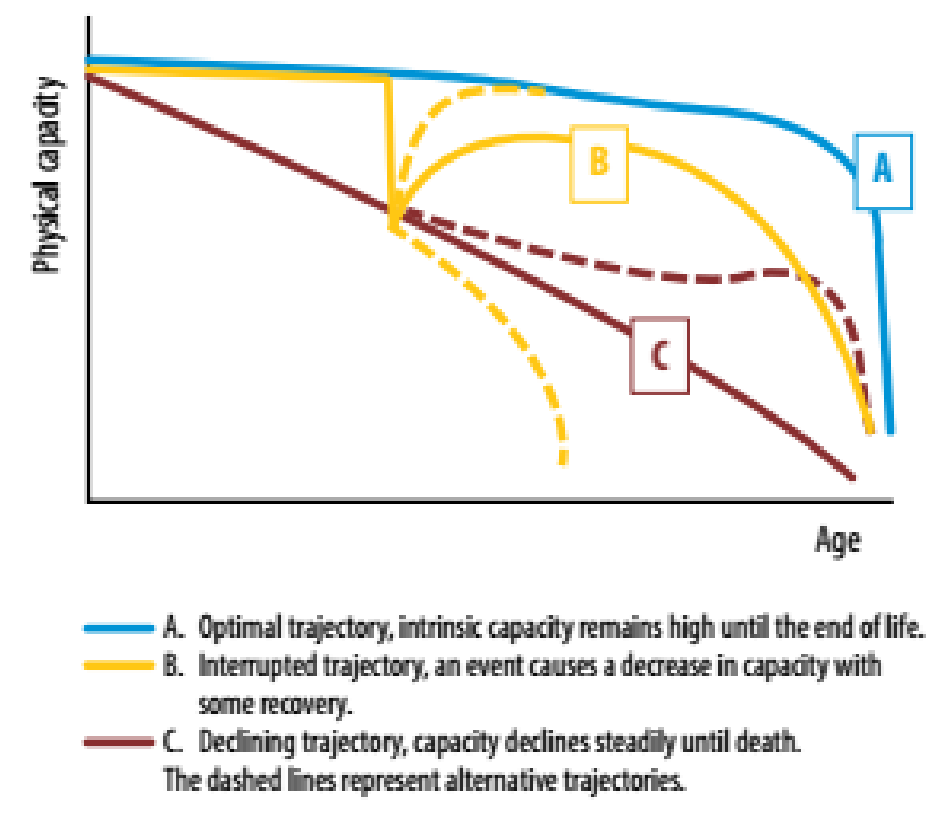

Fig. 1. Three hypothetical trajectories of physical capacity

In Fig. 1, individual A can be considered as having the optimal trajectory, in which intrinsic capacity remains high until the end of life. Individual B has a similar trajectory until a point when an event causes a sudden fall in capacity, followed by some amount of recovery and then a gradual deterioration. Individual $\mathrm{C}$ has a steady decline in function. Each trajectory sees the person die at around the same age, but the levels of physical capacity they have enjoyed in the interim are very different [7].

From the beginning of the initial starting point in Fig.1, each individual's goal is to experience the same with the A locus, but with some exceptions, leading to the decline in physical function, such as accidents, or lack of objective medical conditions, resulting in changes, such as individual B and individual C. And these individuals through health behaviors or drug therapy may have a better track, to measure the function and the possible mechanism of understanding and evaluation at the event, can help to determine the life of people have the most significant effect of the intervention measures applied [8].

\section{Conclusions}

The population aging is to reduce the labor force, increased elderly dependency ratio, the social security fund expenditure increase in elderly population occupied all the social resources to increase the share of aging, now has become a serious challenge faced by countries. In the face of the challenge at the same time, we should also be fully aware of the elderly population is a valuable resource, as the saying goes, "there is an old house as a treasure, they can use their years of accumulated social and cultural experience for the social construction of our building blocks, make a 
significant contribution. Therefore, how to play the role of this valuable resource is the key to meet the challenge.

\section{References}

[1].Fei Shen, Analysis of the impact of population aging on China's labor supply,2014,Nanjing University of Finances and Economics.

[2]. Fang Cai, Demographic transition, demographic dividend and sustainability of economic growth -- on how full employment promotes economic growth. Population Research, 2004. 28(2): P2-9.

[3]. You Xiao, Research Report on the development trend of population aging in China. Human Rights, 2006(2): P60-60.

[4]. Healthy China 2030: to build and share to achieve national health, 2016. 44(21).

[5]. Qingcai Wu, 《Decision of the Central Committee of the Communist Party of China on several major issues of comprehensive deepening reform》. Ideological and moral education, 2014(3): P28-28.

[6]. Peng Du, Promoting healthy aging - conceptual change and Policy Innovation: an interpretation of the WHO's global report on aging and health. Aging Research, 2015(12).

[7]. Organization, W.H.,World report on aging and health. 2015.

[8]. OMS, Closing the gap in a generation: health equity through action on the social determinants of health. Final report: executive summary. Global Health Promotion, 2008. 16: p. 07-08. 